\title{
EDUCAÇÃO SUPERIOR E DESENVOLVIMENTO NA GUINÉ-BISSAU CONTRIBUIÇÕES, LIMITES E DESAFIOS
}

\author{
HIGHER EDUCATION IN THE DEVELOPMENT OF GUINEA-BISSAU: CONTRIBUTIONS, \\ LIMITATIONS AND CHALLENGES
}

EDUCACIÓN SUPERIOR Y DESARROLLO EN GUINÉ-BISSAU: CONTRIBUCIONES, LÍMITES Y DESAFÍOS

Quecoi Sani

Mestrado em Desenvolvimento Regional (PPGDR/UTFPR Campus Pato Branco Docente da Escola Nacional de Administração (ENA) | Guiné-Bissau E-mail: quecoisani@yahoo.com.br

Marlize Rubin Oliveira

Doutorado em Educação. Docente do PPGDR/UTFPR Campus Pato Branco | Brasil. E-mail: rubin@utfpr.edu.br

\author{
REVISTA PEDAGÓGICA \\ Revista do Programa de Pós-graduação em Educação da Unochapecó | ISSN 1984-1566 \\ Universidade Comunitária da Região de Chapecó | Chapecó-SC, Brasil \\ Como referenciar este artigo: SANI, Q. OLIVEIRA, M. R. Educação superior e desenvolvimento na Guiné-Bissau: contribuições, \\ limites e desafios. Revista Pedagógica, Chapecó, v.16, n.33, p. 127 - 152, Jul./Dez. 2014.
}

\begin{abstract}
RESUMO: O artigo apresenta resultados de uma pesquisa documental e exploratória que analisou a educação superior no desenvolvimento da Guiné-Bissau - suas contribuições, limites e desafios. Participaram doze instituições da Guiné-Bissau: oito de Educação Superior, dois ministérios e um instituto nacional de pesquisa. Os resultados demonstram quais seriam as principais contribuições da educação superior para a Guiné-Bissau: maior número de cidadãos formados, administração pública eficaz e eficiente, maior produtividade econômica nacional e diminuição da pobreza. Há muitos limites para o desenvolvimento, dentre eles: o início tardio e ainda incipiente da educação superior, a falta de qualificação de docentes e a falta de infraestrutura, o baixíssimo Orçamento Geral de Estado para a educação. A educação superior representa um desafio premente para o País para a concretização do desenvolvimento almejado por todos.
\end{abstract}

PALAVRAS-CHAVE: Guiné-Bissau. Desenvolvimento. Educação Superior.
ABSTRACT: The paper presents results of a documentary and exploratory research that examined higher education in the development of Guinea-Bissau - their contributions, limitations and challenges. Participated in twelveinstitutions of Guinea-Bissau: Eight of Higher Education, two ministries and a national research institute. The results show what are the main contributions of higher education for Guinea-Bissau: high number of trained citizens, effective and efficient public administration, major national economic productivity and poverty alleviation. There are many limits to development, including: the late start and incipient of higher education, the lack of qualification of teachers and the lack of infrastructure, the very low national budget for education. Higher education represents a pressing challenge for the country to achieve the desired development for all.

KEYWORDS: Guinea-Bissau. Development. Higher Education. 


\section{INTRODUÇÃO}

O desenvolvimento é um assunto que tem preocupado várias nações, com intuito de dar o acesso aos cidadãos o bem-estar de que precisam. Não obstante, o modo de promover o desenvolvimento depende de país para país, pode-se dizer que muitos países têm-no conquistado porque apostaram na formação do homem como elemento principal para alcançá-lo.

O presente artigo apresenta recortes de uma pesquisa documental e de campo exploratória, realizada junto ao ProgramadePós-Graduação em Desenvolvimento Regional, da UTFPR Câmpus Pato Branco. A pesquisa objetivou investigar a situação da educação superior na GuinéBissau da independência - 1974 a 2011, especialmente a contribuição da educação superior no desenvolvimento do País. A coleta de dados pautou-se em documentos oficiais, tais como leis, decretos, boletins, a partir doano de 1974 a 2011, e envolveu doze instituições da Guiné-Bissau, sendo: oito instituições da Educação Superior, dois ministérios e dois institutos, quais sejam: Escola Superior da Educação (ESE), Escola Nacional de Administração (ENA), Escola Nacional de Saúde (ENS), Universidade Jean Piaget (UJP), Universidade Lusófona da Guiné (ULG), Universidade Colinas de Boé (UCB), Universidade Católica de África Ocidental (UCAO), Faculdade de Direito de Bissau (FDB), Instituto Nacional de Estudos e Pesquisas (INEP), Instituto Nacional de Desenvolvimento da Educação (INDE), Ministério da Educação Nacional, Juventude, Cultura e Desportos, Ministério da Economia, e nestas os seus dirigentes, os que se dispuseram a participar da pesquisa.

A escolha destas instituições ocorreu por estarem em funcionamento e oferecendo educação superior em Bissau; em relação aos Ministérios da Educação e da Economia a opção se deu em razão de que ambos influenciam fortemente as políticas nacionais; e os institutos em razão de se relacionarem com a educação superior no País e pela possibilidade de acesso aos seus Bancos de Dados educacionais.

Entretanto, durante a pesquisa de campo, realizada no período de2012 e 2013, pela dificuldade de obtenção de dados junto à diretoria geral de algumas instituições de ensino superior, não nos foi possível obter informações concretas a respeito de sua criação, por isso, não foram mencionadas.

As fontes teóricas consultadas pautaram-se em estudos de autores como Augel (1998, 2007, 2009), Semedo (2011), Sucuma (2013), dentre outros, além de documentos, tais como: Segundo Documento de Estratégia Nacional de redução da Pobreza (DENARP II), Projeto de Apoio ao Ensino Superior (PAES), no espaço da União 
Econômica Monetária Oeste Africano (UEMOA), boletins oficiais, entre outros.

Em vista do exposto, apresenta-se inicialmente um breve cenário socioeconômico e educacional da GuinéBissau; seguido de um panorama da educação superior (1974-2010); na sequência, apresenta-se possíveis contribuições, limites e desafios da educação superior para o desenvolvimento da Guiné-Bissau, e por fim, as conclusões do estudo.

\section{DESENVOLVIMENTO SOCIOECONOMICO E EDUCACIONAL NA GUINÉ-BISSAU: BREVES CONSIDERAÇÕES}

A República da Guiné-Bissau é um país que se tornou independente de Portugal em 1974, através de luta armada, e ao longo dos anos tem enfrentado graves problemas relacionados ao seu desenvolvimento. Está situada na costa ocidental da África, tem $36.125 \mathrm{~km}^{2}$ e uma população de 1.6 mil de habitantes. Tem fronteira com Senegal a norte, a leste e sudeste com a República da Guiné-Conacry e ao sul e oeste com Oceano Atlântico. O território está dividido pela parte continental e a parte insolar constituído por cerca de 40 ilhas, ainda com vários rios, dentre os principais são: rio Cacheu, Buba, Geba, Mansoa, Corubal. (Semedo, 2011, p.19).

A principal economia do país reside na exportação de castanha de caju e no acordo de pesca com a União Europeia. A maioria da sua população encontra-se no campo e vive da prática da agricultura de subsistência. O país produz e exporta, por ano, 135500 toneladas de castanha de caju, o que rende 60 milhões de dólares por ano, dependendo da conjuntura econômica mundial. No continente africano, situa-se na terceira posição no ranking dos países produtores de castanha de caju e sexta a nível mundial (Denarp II, 2011, p.78). A moeda da Guiné-Bissau é o Franco Comunidade Financeira Africana (CFA), símbolo é (XOF). Também usada por mais sete países, quais sejam: Benim, Burquina Faso, Costa do Marfim, Mali, Níger, Senegal e Togo.

A Guiné-Bissau, após a independência em 1974, passou a ser dirigida pelo Partido Africano da Independência da Guiné e Cabo-Verde (PAIGC), até nos anos de 1990, período em que ocorreram as primeiras eleições multipartidárias no país ganhas pelo partido libertador. Contudo, desde que o país assumiu a democracia nunca conheceu a paz governativa, e essa instabilidade política contribuiu sobremaneira para o atraso no desenvolvimento em todos os sectores da vida nacional como na economia, saúde, educação, justiça, infraestruturas, dentre outros setores. (Sucuma, 2013, p.40). 
De acordo com DENARP II (2011), as constantes instabilidades políticas têm contribuído não só para o fraco crescimento econômico do país, mas também para o baixo índice do desenvolvimento humano (IDH). Segundo o Programa das Nações Unidas para o Desenvolvimento (PNUD), citado pelo referido documento, em 2010, "o país conta com IDH de 0,289, encontrando-se na $164^{\mathrm{a}}$ posição num total de 169 países".

Ainda o mesmo documento cita que "entre 2000 e 2010, o País registrou uma taxa de crescimento médio anual do Índice Desenvolvimento Humano de 0,9\% contra uma média de $2.1 \%$ na África subsaariana e de 1,68\% nos países com IDH muito baixo". E identifica dois fatores que contribuíram para o baixo IDH do País, quais sejam: pobreza generalizada, com baixo rendimento monetário e a esperança média de vida (48,6 anos), resultante das dificuldades do acesso e da qualidade de serviço de saúde. Este fato é aliado com a taxa de crescimento populacional de $2,5 \%$ e com a taxa de crescimento econômico, que pouco ultrapassa em média 3\% entre 2000 e 2010. (Denarp II, 2011).

Em face disso, Guiné-Bissau é considerado um dos países mais pobres do mundo, devido à sua fragilidade em vários sectores como, por exemplo, educação e saúde. O Governo, ciente desta preocupação, adaptou o DENARP II, o qual nos informa que:

Em termos de realização dos ODM, a GuinéBissau dificilmente conseguirá atingir os objectivos do desenvolvimento do milénio, com excepção do sector da educação que tem registado progressos notáveis. Entre os indicadores que acusaram recuo, destacase a pobreza que degradou entre 2002 e 2010. Com efeito, os resultados do ILAP $2 / 2010$ indicam que $69,3 \%$ dos guineenses são pobres e 33\% são extremamente pobres, ou seja, mais 5 e 13 pontos percentuais, respectivamente, comparados com o ano 2002. Isto mostra claramente o agravamento da extrema pobreza. Em Bissau, a pobreza manteve-se constante (51\%), enquanto se agravou nas outras regiões (3 sobre 4 afectadas, contra 7 em cada 10 pessoas atingidas em 2002). As regiões mais atingidas em 2010 pela pobreza são, principalmente, Oio, Bafatá, Tombali / Quinara e Gabu e a pobreza extrema afecta sobretudo Oio, Cacheu, Bafata, Tombali e Quinara. A pobreza generalizada tem um impacto directo sobre a situação das crianças. De facto, em 2010, para o conjunto do país, 57\% das crianças de 5-14 anos são trabalhadoras, com uma forte proporção nas zonas rurais (65\%) em relação ao meio urbano (45 \%). (Denarp II, 2011, p.6). 
Na área da saúde, o país tem enfrentado problemas graves, seja pela falta de infraestruturas sanitárias, seja pela falta de recursos humanos e materiais necessários para esta área. Assim sendo, esta realidade reflete-se, também na capacidade de produção da população guineense, bem como na fraca esperança média de vida.

$\mathrm{O}$ documento menciona que as principais causas que constituem morbi-mortalidade da população são as doenças transmissíveis, incluindo o VIH/SIDA1 e as complicações obstétricas e neonatais. Desse modo, apesar de os progressos realizados no domínio dos cuidados primários de saúde, o paludismo continua a ser uma doença endémica de transmissão estável e de prevalência elevada. Os grupos mais frágeis ao paludismo são crianças menores de 5 anos e mulheres grávidas.

O documento alerta que, para além das doenças transmissíveis e doenças preveníveis pela vacinação, destacam-se a má nutrição, como o primeiro problema de saúde pública entre as doenças não transmissíveis. Ela dá um assinalável contributo para a mortalidade tanto infantojuvenil como materna. No quadro clínico das doenças não transmissíveis, fala-se das doenças cardiovasculares (DCV), particularmente a hipertensão arterial, a diabetes e outras doenças crónico degenerativas, cancro.

Outra situação precária no país é o acesso à agua potável e a serviços de saneamento básico, fatores que contribuem severamente para a contração de doenças contagiosas em todos os níveis sociais, e têm contribuído na persistência tanto de doenças endêmicas, quanto na baixa esperança média de vida dos cidadãos.

Pela análise demonstrada em DENARP II (2011), a Guiné-Bissau está mal posicionada para atingir os ODM até 2015. Os atrasos registados na implementação das políticas públicas ambiciosas e eficazes, motivados pelas instabilidades institucionais que permanecem há mais de duas décadas explicam o agravamento da pobreza em todas as regiões do país. Dessa forma, segundo o documento em questão, a Guiné-Bissau propõe-se adiar a realização dos ODM para 2020, adaptando estratégias de aceleração de certos ODM para 2015, com o objetivo de obter ganhos imediatos que exigem políticas setoriais mais direcionadas e focalizadas e meios consequentes para atingir os diferentes objetivos no horizonte 2015 e 2020.

Neste caso, as realizações imediatas situar-se-ão nos seguintes sectores: a) Educação primária e secundária; b) Saúde e HIV/SIDA; c) Água e saneamento; d) Desenvolvimento da agricultura e valorização dos produtos locais na óptica da segurança alimentar.

No que concerne à problemática do ambiente empresarial, não se poderia falar de progressos neste domínio, porque, como se referiu acima, as constantes 
instabilidades políticas recorrente no país não proporcionaram atração de investimento empresarial. DENARP II (2011, p. 72) avalia que há "melhoria do ambiente de negócios e promoção do sector privado. Neste mesmo documento, dados do relatório "Doing Business", elaborado pelo Banco Mundial, mostram que a GuinéBissau está classificada entre os últimos países em termos de adequação do ambiente de negócios: $173^{\circ}$ sobre $175 \mathrm{em}$ 2005 / 2006 e $181^{\circ}$ sobre 183 em 2008/2009".

Neste caso, as poucas empresas nacionais que existem no País têm funcionado com sérios problemas de rentabilidade, quer pela falta de acompanhamento de mercado de concorrência, quer pela incapacidade de o país ter criado condições do desenvolvimento de negócio. Por exemplo, uma das questões que cria constrangimento para um clima empresarial rentável, é a problemática da falta de corrente elétrica no país. Com isso, as empresas têm dificuldade em arcar com a produção de corrente elétrica tendo em conta o seu alto custo que a sua produção reflete na vida da empresa. Por outro lado, as empresas que se arriscam na produção da energia elétrica própria acabam por refletir no custo do produto final, fato que torna este último fora de poder de compra de maioria da população, já que boa parte dos cidadãos do país encontra-se num estado de pobreza.

A principal fonte da economia do país reside na agricultura, responsável em garantir a base alimentar das famílias guineenses e o maior empregador dos cidadãos, uma vez que a maioria da população ainda vive no campo. Contudo, a agricultura na Guiné- Bissau é ainda tradicional, isto é, de subsistência. O país tem produzido diferentes produtos para o consumo, como arroz (dieta base), milho, feijão, mancarra (amendoim), batata doce, mandioca, etc. O maior destaque da agricultura do país é a produção de castanha de caju, na medida em que tem envolvido vários intervenientes no processo (agricultores, pequenos comerciantes, empresários e o Estado), já que a boa parte da sua produção é exportada para estrangeiro, conforme afirmado em DENARP II (2011, p.26):

O caju é principal produto de exportação do pais. O desenvolvimento do seu mercado de exportação constitui um sucesso popular afetando largamente o mundo rural. As exportações de castanha de caju, com apenas 1. 200 toneladas em 1970 conheceu um salto quantitativo, atingindo cerca de 100000 toneladas em 2005, 135500 ton. em 2009 e, 122300 em 2010. Contudo, somente 4\% da produção é transformada a nível nacional, o restante é exportado sob forma bruta. A castanha, ocupando $47 \%$ da superfície cultivada e implicando $80 \%$ das populações rurais nas atividades agrícolas, é um setor 
estagiário para a criação de emprego e redução da pobreza.

Entretanto, a descrição destes cenários precários em vários domínios da vida social, econômica e política do país, ainda não nos permite poder falar do desenvolvimento, apesar de o objetivo de Estado em criar o desenvolvimento para os cidadãos poderem desfrutar "das liberdades". Neste caso, AmartyaSen (2000, p.18) ajuda-nos a entender a situação, ao dizer que:

\begin{abstract}
A ausência de liberdades substantivas relaciona-se diretamente com a pobreza econômica, que rouba das pessoas a liberdade de saciar a fome, de obter uma nutrição satisfatória ou remédios para doenças tratáveis, a oportunidade de vestirse ou de morar de modo apropriado, de ter acesso a água tratada ou saneamento básico. Em outros casos, a privação de liberdade vincula-se estreitamente a carência de serviços públicos e assistência social, como por exemplo ausência de programas epidemiológicos, de um sistema bem planejado de assistência medica e educação ou de instituições eficazes para a manutenção da paz e da ordem locais. Em outros casos, a violação da liberdade resulta diretamente de uma negação de liberdades políticas e civis por regimes autoritários e de restrições impostas à liberdade de participar da vida social, política e econômica da comunidade.
\end{abstract}

Diante desse cenário, apostar na educação, dabásica à educação superior deve ser um compromisso transcendental no sentido de formar cidadãos qualificados para enfrentarem a árdua tarefa do desenvolvimento que o país tem reclamado. Entende-se que é através da educação que podemos ter cidadãos comprometidos com a pátria, valorizando a história, o respeito pela democracia, a cidadania responsável e a luta pelo progresso econômico sustentável.

Assim sendo, o desafio que nos espera é dinamizarmos a nossa educação, uma vez que sem educação não há condições para o desenvolvimento de que o país precisa.

\title{
CENÁRIO DA EDUCAÇÃo SUPERIOR NA GUINÉ-BISSAU - 1974 A 2011
}

De acordo com Augel (1998, p.24), "ao raiar a independência, a Guiné- Bissau possuía dezessete quadros de formação média e quatorze de formação universitária”. Nesta condição, tornar-se-ia muito difícil para o país trilhar 
o caminho do desenvolvimento, sendo uma das razões da luta de libertação nacional. As autoridades, cientes desta situação, assinaram acordos de formação técnico e superior dos guineenses nos principais países, entre os quais, Bulgária, URSS, Cuba, Brasil, França, Argélia, Senegal e Portugal. Contudo, a ideia era sempre apetrechar o país de estruturas de formação que pudessem albergar maior número de estudantes em função das necessidades prementes do país. (Sanhá, 2009, p.37).

Para ilustrar melhor tal situação, relata-se a criação de algumas instituições de formação do país, com base em documentos oficiais e em literatura pertinente ao tema, tais como: Guia do Professor (1991), relatório do Projeto de Apoio ao Ensino Superior (PAES, 2010), no espaço da União Econômica Monetário Oeste Africano (UEMOA), Sanhá (2009), Augel (2009), Sucuma (2013) e Hugo Monteito (2013). É importante ressaltar aqui que informações sobre o ano da criação de algumas instituições se contradizem, dependendo da fonte de pesquisa.

Sobre a criação de instituições de ensino superior, documentos apontam que em 1974 surgiu a Escola Nacional de Saúde, cujo objetivo era formar quadros técnicos para o sistema nacional de saúde.

Em 1975, criou-se a escola de Formação Amílcar Cabral, em Bolama, para a formação de professores de ensino básico.

Em 1979, foi aberta a Escola Normal Superior TchicoTé para a formação de professores para o ensino secundário, com duração de três anos, com grau de bacharelato.

Mais tarde, em 2001, deu-se o início do curso de Licenciatura em Língua Portuguesa para a formação de professores para o ensino secundário e superior, apoiado pelo Instituto Camões em Bissau, por intermédio do governo Português.

No ano de 1982 , com a necessidade de se resolvera falta de quadros técnicos na administração pública e privada, foi criado o Centro de Formação Administrativa (CENFA), através do Instituto de Formação Técnica e Profissional (INAFOR). Atualmente, por decisão governamental, este foi substituído pela Escola Nacional de Administração (ENA), oferecendo cursos técnicos e superiores em Contabilidade e Administração.

Em 1986, através da cooperação com Cuba, foi aberta a Faculdade de Medicina, com o objetivo de dotar o país de quadros para a saúde pública. Contudo, por causa da sua decadência financeira foi integrada em 2004 à Universidade Amílcar Cabral.

Ainda em 1986, foi criada a Escola Nacional de Educação Física e Desportos (ENEFD), para a formação de professores de educação física e desportos. 
Em 1990, através da cooperação Portuguesa, abriu-se a Faculdade de Direito de Bissau (FDB), oferecendo curso de Direito, com grau de Licenciatura. Recorda-se que, em 1979, o governo criou a Escola de Direito que oferecia curso técnico nas áreas Jurídicas que depois deu lugar a FDB, em 1990.

Em 2003, foi aberta a primeira universidade pública do país, a Universidade Amílcar Cabral, (UAC). Mas, em 2007, o governo, alegando a impossibilidade de sustentar esta universidade, assinou um contrato de cedência à Universidade Lusófona de Portugal, surgindo, assim, a Universidade Lusófona da Guiné, (ULG). Esta oferece os seguintes cursos: Economia, Administração e gestão de Empresa, Sociologia, Comunicação Organizacional e Jornalismo, Pedagogia e Ciências de Educação, Engenharia Informático, Arquitetura, Enfermeiro e Ciências Médicas.

Ainda, em 2003, foi criada a primeira universidade privada do país, pela iniciativa de um grupo de intelectuais guineenses, Universidade Colinas de Boé, (UCB), que ministra os seguintes cursos: Administração Pública e Economia Familiar, Gestão e Contabilidade, Comunicação Social e Marketing, Engenheiro Informático, Engenheiro em Construção Civil e Engenheiro Eletrônico.

Em 2007, foi aberta a Universidade Católica da África Ocidental (UCAO) oferecendo curso de Administração, na capital Bissau.

Em 2008, foi criado o Instituto Superior de Gestão de Bissau (ISGB), oferecendo os cursos de Gestão, Turismo, Contabilidade, Economia e Comércio. Um ano depois, em 2009, houve a criação de Sup Management (instituição de ensino superior em Bissau), que oferece cursos de Gestão e Informática. Sabe-se que, infelizmente, já não funcionam estas duas instituições, (ISGB e Sup Management), por motivos que desconhecemos.

Em 2010, criou-se a Universidade Jean Piaget, já com instalações próprias, que está a oferecer cursos de Ciências de Saúde e do Ambiente, Tecnologias, Ciência Política, da Educação e do Comportamento, assim como unidade de Ciência Econômica e Empresarial.

Portanto, a partir da criação de instituições universitárias no país, depreende-se que tem crescido o número de instituições de formação, quer públicas, quer privadas. Contudo, nota-se lacunas na oferta de cursos, pois nenhuma destas oferece cursos de Agricultura e de Pesca, áreas consideradasbase da nossa economia, segundo DENARP II (2011). Quanto à sua localização, quase todas concentram-se na capital, Bissau, com exceção da FM/ ENS, Escola de formação "Amílcar Cabral”, situada em Bolama, e da Escola Nacional de Administração (ENA) com delegações regionais em Bafatá, Canchungo e Buba.

Assim sendo, anualmente, muitos jovens residentes em regiões afastadas seguem para a capital à procura de melhoria 
para a sua formação. A socióloga, Valéria Villa Verde (2004, p.5) afirma que "o enfoque territorial permite pensar o desenvolvimento para além dos centros urbanos, onde os pequenos municípios são estrelas de uma constelação".

Em síntese, no quadro 1, demonstra-se o estágio da educação superior no país, de 1974 a 2010, no que concerne à sua implantação e à sua evolução.

Quadro 1: Ano de Implantação, Nível de Ensino, Administração, Local de Funcionamento

\begin{tabular}{|c|c|c|c|}
\hline Ano & $\begin{array}{l}\text { Instituição de Ensino } \\
\text { Superior } \\
\text { Instituição de EnsinoTécnico }\end{array}$ & $\begin{array}{l}\text { Pública/ } \\
\text { Privada }\end{array}$ & Local \\
\hline 1974 & Escola Nacional de Saúde (ENS) & Pública & Bissau \\
\hline 1975 & $\begin{array}{l}\text { Escola de Formação Amilcar } \\
\text { Cabral }\end{array}$ & Pública & Bolama \\
\hline 1979 & $\begin{array}{l}\text { Escola Normal Superior TchicoTé, } \\
\text { atual (Escola Superior da } \\
\text { Educação que integra Escola de } \\
\text { Formação Amilcar Cabral, Escola } \\
\text { Nacional de Educação Física e } \\
\text { Desportos e Escola de Formação } \\
17 \text { de Fevereiro }\end{array}$ & Pública & \multirow{11}{*}{ Bissau } \\
\hline 1982 & $\begin{array}{l}\text { Centro de } \text { Formação } \\
\text { Administrativa (CENFA), atual } \\
\text { Escola Nacional de Administração } \\
\text { (ENA) }\end{array}$ & Pública & \\
\hline 1986 & Faculdade de Medicina & Pública & \\
\hline 1986 & $\begin{array}{l}\text { Escola Nacional de Educação } \\
\text { Física e Desportos (ENEFD) }\end{array}$ & Pública & \\
\hline 1990 & Faculdade de Direito de Bissau & Pública & \\
\hline 2003 & $\begin{array}{l}\text { Universidade Amílcar Cabral } \\
\text { (UAC) atual Universidade } \\
\text { Lusófona da Guiné (ULG) }\end{array}$ & Privada & \\
\hline 2003 & $\begin{array}{l}\text { Universidade Colinas de } \\
\text { (UCB) }\end{array}$ & Privada & \\
\hline 2007 & $\begin{array}{l}\text { Universidade Católica da África } \\
\text { Ocidental (UCAO) }\end{array}$ & Privada & \\
\hline 2008 & $\begin{array}{l}\text { Instituto Superior de Gestão de } \\
\text { Superior de Bissau (ISGB)1 }\end{array}$ & Privada & \\
\hline 2009 & Sup Management ${ }^{2}$ & Privada & \\
\hline 2010 & Universidade Jean Piaget & Privada & \\
\hline
\end{tabular}

Fonte: Adaptado de: Sanhá (2009), Augel (2009), PAES (2010), Sucuma (2013) e Hugo Monteito (2013).

Nota-se que a Guiné-Bissau iniciou tardiamente a implantação da educação superior, seja pela sua independência tardia, em 1974, seja porque o país colonizador nunca demonstrou interesse em ofertar o ensino para além do básico. 
Nesse aspecto, vale destacar que a primeira instituição de ensino de Bissau data de 1958 denominado Liceu Honório Barreto, atual Liceu Nacional KwameNkrumah. (SEMEDO, 2011, p.47).

De acordo com Sucuma (2013, p.76), por meio de dados da Direção Geral dos Estudos, Planificação e Avaliação do Sistema Educativo (DGEPASE), pertencente ao Ministério da Educação Nacional, o país contava, até ao letivo 2007/2008, com 11 instituições de formação. Com efeito, um dado importante a registar é o aumento das instituições de formação de inciativa privada no país, principalmente nos anos 2003 a 2012.

Nessa lógica, em 2003, é criado o Centro de Formação "São Leonardo Morialdo", vindo a funcionar somente em 2008. Este oferece cursos de Administração, Contabilidade, Secretariado, Gestão Hoteleira e Turismo, Comércio e Marketing e Jornalismo. Segundo o seu diretor, "o centro de formação é de nível médio, no ano letivo 2012/2013, conta com 480 alunos, tem sede em Bissau (capital) e polos de formação, em algumas cidades das regiões do país como: Gabú, Canchungo, Buba”.

No ano 2004, foi aberto o Centro de Formação "São João Bosco"- técnico e profissional, que oferece os seguintes cursos, em Bissau, capital do país: Administração, Contabilidade e Turismo.

No ano letivo 2011/2012, criou-se o Centro de Formação "Luís Inácio Lula da Silva", que ofereceos cursos técnicos: Gestão financeira, Gerência executiva em Marketing, Gestão de Recursos Humanos, com duração de dois anos letivos (Especialização); Estatística Aplicada, Contabilidade, Administração e Autarquias Locais, Três anos letivos (Médios).

Ainda em 2011/2012, criou-se o Instituto Binhôbolo, oferecendo cursos na área de saúde.

Portanto, a partir dos dados mencionados, podese afirmar que o país conta, até o ano de 2013, com 15 instituições entre as de formação técnica e superior. Neste caso, para um país como a Guiné-Bissau, com uma população de 1.6 mil habitantes, é um dado encorajador para o desenvolvimento das Instituições de Formação Superior (IFS). Contudo, as IFS, quer públicas, quer privadas, têm funcionado com recursos proveniente das taxas de matrícula e mensalidades pagas pelos alunos, ainda com algum atraso do pagamento, visto que a maioria dos alunos têm dificuldades financeiras.

Portanto, a realidade da educação superior faz crer em um futuro encorajador no que se refere ao número das instituições de ensino. Mesmo com as dificuldades de pagamento das taxas de inscrição e das mensalidades cobradas, tem havido a cada ano um número crescente de jovens com interesse em continuar os estudos superiores. Sobre tal situação, Augel (2009, p.144) comenta: 
1 Estima-se o número de alunos entre 5000 e 6000 em 2010.
Não obstante a serem cobradas a taxa de inscrição e mensalidades em ambas universidades, e mesmo levando em conta o baixo poder aquisitivo da população, a demanda é bastante grande: para o ano 20042005, encontravam-se inscritos nos diferentes estabelecimentos do ensino superior cerca de 4000 estudantes, sendo a proporção dos estudantes do sexo feminino de um terço.

Segundo PAES (2010, p.9), apesar de as dificuldades da recolha de dados fiáveis, como avança o Ministério do Plano, pode-se "évaluentlenombre d'étudiants entre 5000 et 6000 pour l'année 2010"1.

Pode-se perceber também que, se por um lado, tem havido proliferação de instituições de educação superior, de outro, há falta de docentes qualificados, bem como há falta de infraestruturas adequadas. Sobre isso, Augel assevera que:

A fraca qualificação do corpo docente, como lembra João "Hugo" Monteiro, é um dos mais graves problemas que enfrenta a ambição universitária guineense, na menina em que as instituições funcionam fundamentalmente com professores locais, sem qualificação apropriada, dispondo de poucos meios, praticamente sem bibliotecas especializadas, por exemplo. A docência é ainda, infelizmente, assegurada basicamente por licenciados, alguns Mestres e muito raros doutores. (Augel, 2009, p.145).

De acordo com DENARP II (2011, p.72), o país é iminentemente agrícola, ainda que tradicional, e com grandes potencialidades do pescado. Porém, as instituições de formação superior do país ainda não oferecem cursos, quer de agricultura, quer de pescas, áreas consideradas base da nossa economia.

Nesta condição, segundo Augel (2009), a GuinéBissau carece de identidade nacional, por isso, a escola, em especial, a educação superior, pode ser um complemento para tal desejo.

A Guiné-Bissau está ainda sem identidade nacional consolidada, com tradições culturais, lealdade étnico - locais e convicções de pertencimento muitas vezes mais claras em relação à própria comunidade étnica do que à "nação" guineense propriamente dita. É dentro de tal contexto, e tentando descortinar possíveis novas perspectivas para a Guiné-Bissau, que desejo falar da universidade e do ensino superior, falar do papel da universidade para a construção da guineidade. (Augel, 2009, p. 147). 
Nesta perspectiva, acreditamos, juntamente com Augel (2009), que a educação superior é um meio necessário para minimizar problemas políticos e sociais do país, porque apostar na educação é acreditar no poder da ciência para a obtenção de uma sociedade democrática, responsável, que preserve valores nacionais em detrimento dos valores pessoais, que lute pela unidade nacional.

Na sequência, tendo por base informações contidas em decretos governamentais e em autores como Augel (2007, 2009), Sucuma (2013) e no Projeto de Apoio ao Ensino Superior (PAES), no espaço da UEMOA, apontamse algumas importantes medidas implementadas pelo governo sobre o sistema educativo nacional e, em especial, o da educação superior.

Em 1974 o governo da Guiné-Bissau criou a Escola Nacional de Saúde (ENS), com objetivo de formar técnicos para o sistema nacional de saúde; pelo Decreto $n^{0} 22 / 79$ cria-se a Escola de Direito, que viria a ser Faculdade de Direito de Bissau (FDB), através do decreto $n^{0} 34 / 90$, com intuito de formar quadros na área jurídica para afirmação de Estado de Direito no país.

Pelo Decreto $\mathrm{n}^{0} 31 / 84$ criou-se o Instituto Nacional de Estudos e Pesquisa (INEP), com missão de desenvolver pesquisas nas áreas sociais. De acordo com Sucuma (2013), em 1986, o governo cria a Faculdade de Medicina para a formação de quadros superiores para o sistema nacional de saúde através da cooperação cubana.

Pelo Decreto-Lei no 6/99 criou-se a Universidade Lusófona "Amílcar Cabral" (ULAC), pública, que passou a funcionar a partir de 2003 e, em 2007, o governo cedeu-a para a Universidade Lusófona de Lisboa. Assim, em virtude de tal situação criou-se a Universidade Lusófona da Guiné (ULG). Portanto, sabe-se que o governo reabriu a ULAC, através do Ofício no 1254, do Gabinete do Primeiro Ministro, de 29 de Novembro de 2011. A instituição já tem uma nova Reitora, com a pretensão de fazê-la funcionar em 2013/2014, apesar das adversidades políticas que têm rondadoa proposta.

Nos anos 2000, o Governo adotou a Declaração de Política Educativa e o Plano Nacional de Ação (PNA)Educação Para Todos (EPT) - (2000).

Através de um grupo de intelectuais guineenses, em 2003, criou-se a Universidade Colinas de Boé (UCB), privada; em 2009 é extinto o Centro de Formação Administrativa (CENFA) e criada a Escola Nacional de Administração, designada ENA; é aprovado o Instituto Piaget a exercer as suas atividades no País e a Universidade Jean Piaget; em 2010 é adaptada a revisão curricular do ensino secundário, que implica introdução do $12^{\circ}$ ano de escolaridade; é criado e aprovado os estatutos da Escola Superior da Educação (ESE), que passa a integrar as seguintes escolas de formação de professores: Escola de 
formação Amílcar Cabral, em Bolama, Escola Normal Superior TchicoTé, 17 de Fevereiro e Escola Nacional da Educação Física; em 2011, criou-se a Lei do Ensino Superior e da Investigação Científica, a Lei da Carreira Docente, e a Lei de Bases do Sistema Educativo.

Com base no exposto, nota-se que o Estado da GuinéBissau tem legislado sobre a educação do país a partir vários documentos oficiais. Contudo, tem faltado o cumprimento das leis para o avanço da educação nacional. Em vista disso, a educação continua a enfrentar sérios problemas que vão desde a falta de professores com qualificação apropriada até a falta de infraestruturas escolares e equipamentos básicos.

Diante do cenário apresentado, nas próximas secções, faz-se o esforço de apresentar alguns elementos que, a nosso ver, poderiam possibilitar contribuições, limites e desafios da educação superior para o desenvolvimento da Guiné-Bissau.

\section{EDUCAÇÃO SUPERIOR NA GUINÉ-BISSAU: CONTRIBUIÇÕES, LIMITES E DESAFIOS PARA O DESENVOLVIMENTO DO PAÍS}

A nosso ver, entendemos que apostar na educação, do básico ao superior, pode ser um dos meios para se lutar contra pobreza, fortalecer a economia, a democracia, paz e a promoção do desenvolvimento. Sobre isso, é ilustrativa uma afirmação de Nascimento (2001),

(...) educação e desenvolvimento são termos concebidos usualmente como distintos, mas sempre apresentados juntos. São, na verdade, dois fenômenos ou processos sociais pensados articuladamente, um remetendo ao outro. Sem, no entanto, deixarem de ter as próprias identidades. Ambos nascem, ou são inventados, no interior daquilo que denominamos normalmente modernidade. A educação, tal como a conhecemos hoje, e o desenvolvimento, tal como o concebemos hodiernamente, são frutos da sociedade moderna. (...) (Nascimento, 2001, p.96).

A educação formal na Guiné-Bissau começou na colonização portuguesa, de 1446 a1974, sendo que neste período um número ínfimo de guineenses teve acesso à escola. Não obstante, a chamada educação informal sempre é observada no país, através de geração em geração. Trata-se de uma educação sem observância das regras pedagógicas, sem currículo, programas e, por vezes, sem a escrita. Ou seja, não obedecia a regras científicas. (Cá, 2009, p.5) 
Portugal pouco investiu na educação da população, em relação a outros países como Inglaterra, França nas suas colônias como Gambia e Senegal, respectivamente. Sobre isso, Augel (1998, p.22-23) destaca que:

Os três regimes tinham como base comum a seletividade e a descriminação dos povos colonizados: apenas os indivíduos de nacionalidade francesa, inglesa ou portuguesa (nata ou adquirida) tinham direito a uma educação que fosse mais além da elementar. Para Portugal, era extremamente crassa a distinção entre indígenas e os assimilados e a educação dos primeiros se limitava ao ensino rudimentar com noções básicas de cálculo e um aprendizado superficial da língua portuguesa. (...) enquanto a Gambia destinava o equivalente a 3,08 dólares para os gastos com a educação para cada habitante, Portugal disponibilizava 0,36 dólares por habitante. Em quanto Senegal já teve em 1903 a sua primeira reforma do ensino e criou em 1948 o seu primeiro estabelecimento do ensino superior e em 1953 a universidade de Dakar era institucionalizada, na Guiné somente em 1941 foi elaborado um estatuto pelo qual o ensino indígena era confiada às missões, tendo sido um ano depois confirmado o monopólio da Igreja católica; em 1948 houve uma regulamentação do ensino rudimentar na Guiné, refeito três anos mais tarde e apenas em 1958 houve uma reforma de ensino secundário e a fundação de primeiro liceu (Honório Barreto) na capital do País(...)

Após a Independência, em 1974, o Partido Africano para a Independência da Guiné e Cabo-Verde (PAIGC) tentou disseminar a educação no país, oportunizando o acesso à escola aos guineenses. Todavia, o país deparavase com graves problemas, como: falta de professores, materiais didáticos, infraestruturas escolares, as sucessivas greves dos professores, exigindo as melhores condições de qualidade de vida no trabalho e permanente instabilidade político militar que acabam tornado muito fraco o nosso sistema de ensino. Nessa direção, afirma Augel (2007, p.72-73), "O número de professores com uma formação pedagógica e acadêmica é mínimo, predominando professores leigos e com um precário preparo. O país não conta até hoje com nenhuma livraria".

Quanto ao sistema educativo nacional, está estruturado da seguinte forma: a Educação Não-Formal e a Educação Formal. A Não-Formal é uma educação abrangente e é direcionada para "alfabetização e educação de base de jovens e adultos; ações de reconversão e aperfeiçoamento profissional, tendo em vista o acompanhamento da evolução tecnológica; educação 
tecnológica; educação dirigida para a ocupação criativa dos tempos livres e educação cívica”. (Boletim Oficial, n. ${ }^{0}$ 13, 2011, p.30-31). A Educação Formal envolve: ensino préescolar, básico, secundário, técnico profissional e superior.

A Guiné-Bissau, com a independência, passou a assinar acordos com alguns países, principalmente os de leste, para a formação de quadros, por meio de incentivos, como bolsas de estudo, dentre outros, visandoo desenvolvimento do país. Contudo, a ideia foi sempre a de ofertar o ensino superior nacional para os cidadãos se formarem localmente.

Nesta perspectiva, o Estado da República da GuinéBissau começou a empreender dinâmicas no sentido de dotar o país com as instituições de formação, com intuito de responder os desafios que o país tinha com relação às necessidades de quadros e consequente desenvolvimento, conforme se pode ler nos trabalhos de Augel (2009), Sanhá (2009), Sucuma (2013), e Monteito (2013).

Portanto, a educação e o desenvolvimento são dois termos que se comunicam. Uma vez que não se pode falar de desenvolvimento sem tereducação de qualidade, que contribuam para o processo complexo de desenvolvimento em seus múltiplos aspectos. Por seu turno, a educação superior da Guiné-Bissau também iniciou-se tardiamente, e desde a independência do país, tem enfrentado vários limites e desafios a superar.

Em vista deste cenário, busca-se apresentar alguns limites, desafios e contribuições da educação superior para o desenvolvimento da Guiné-Bissau.

\section{CONTRIBUIÇÕES}

O desenvolvimento que se quer do País exige um esforço de todos, mas principalmente do Estado, como o seu principal promotor. O termo desenvolvimento, almejado por todos os países do mundo, é permeado por diferentes conceitos ao longo dos tempos.

Nesse sentido, Sen(2000, p.49) defende que "ver o desenvolvimento a partir das liberdades substantivas das pessoas tem implicações muito abrangentes para a nossa compreensão do processo de desenvolvimento e também para os modos e meios de promovê-lo".

Furtado (2000, p.7), mostra-nosque "as sociedades são consideradas desenvolvidas à medida em que nelas o homem logra satisfazer suas necessidades e renovar suas aspirações". O autor (2000) considera a questão do desenvolvimento como um processo global, transformação da sociedade não só aos meios mas também aos fins; processo de acumulação e de ampliação da capacidade 
produtiva, diversificação de consumo, cooperação. Para ele, a rigor, há, pelo menos, três dimensões sobre o desenvolvimento: incremento da eficácia do sistema social de produção, a da satisfação de necessidades elementares da população e a da consecução de objetivos a que almejam grupos dominantes de uma sociedade e que competem na utilização de recursos escassos.

Portanto, Furtado (2000, p. 22) destaca que a "concepção de desenvolvimento de uma sociedade não é alheia à sua estrutura social, e tampouco a formulação de uma política de desenvolvimento e sua implantação são concebíveis sem preparação ideológica”.

Pochmann (2010), falando sobre as questões estratégicas para o desenvolvimento brasileiro de longo prazo, chama a atenção para quatro questões que o país precisa superar, a saber: demografia nacional; desenvolvimento conectado com a sustentabilidade ambiental; situação regional e; investimento produtivo e educacional. Todas as questões citadas dizem respeito à Guiné-Bissau, ainda que, de forma mais preocupante. O País tem registrado aumento populacional sem que a maioria da sua população tenha acesso pleno ao serviço de saúde e educação; a monocultura de castanha de caju substitui a diversificação agrícola, aliada a exploração desenfreada da floresta; a fraca concorrência com os países da sub-região devido a sua fraca economia.

O desenvolvimento é, por assim dizer, um fim desejado por todos os Países. Contudo, a sua concretização depende, não só, do contexto de cada país, mas também, da visão que os gestores têm do conceito e implementação de políticas públicas. Assim, por um lado, há autores que defendem o desenvolvimento como o crescimento econômico, industrialização e, por outro lado, os que acham que o desenvolvimento não se deve resumir ao crescimento econômico, mas sim melhorar significativamente a qualidade de vida das populações no que concerne ao acesso à saúde, educação, a tecnologia, alimentação, vestuário, luz, esperança média de vida, moradia, emprego, lazer, direito àliberdade e à democracia plena.

Nesse sentido, Oliveira (2002, p.38) assevera que:

O desenvolvimento, em qualquer concepção, deve resultar de crescimento econômico acompanhado de melhoria de qualidade de vida, ou seja, deve incluir as alterações da composição do produto e a alocação de recursos pelos diferentes setores da economia, de forma a melhorar os indicadores de bem-estar econômico e social (pobreza, desemprego, desigualdade, condições de saúde, alimentação, educação e moradia. 
O mesmo autor destaca que "em nome do desenvolvimento buscam-se valores crescentes: mais mercadorias, mais anos de vida, mais publicações científicas, mais pessoas com títulos de doutores, dentre vários outros" (Oliveira, 2002, p.41).

Nesta perspectiva, dentre outros, são estes alguns desafios que permeiam a Guiné-Bissau, caso queira se ver o bem-estar social da sua população e dar razão à sua luta para independência nacional.

Atualmente, o desenvolvimento é concebido no sentido de se atender às necessidades das populações atuais semcomprometerageraçãofutura, ou seja, desenvolvimento voltado à sustentabilidade, conformerevela Guimarães, (2001 p. 55), citando a Comissão Mundial sobre o Meio Ambiente e Desenvolvimento (Brundtland, 1987) "o desenvolvimento sustentável é aquele que satisfaz as necessidades das gerações atuais sem comprometer a capacidades das gerações futuras de satisfazer suas próprias necessidades". Ainda para este autor, o centro da atenção de desenvolvimento deve ser o homem.

(...) inserir o ser humano no centro do processo de desenvolvimento, considerar o crescimento um meio, e não um fim, proteger as oportunidades de vida das gerações atuas e futuras e, por conseguinte, respeitar a integridade dos sistemas naturais que permitem a existência da vida no planeta. Neste sentido, hoje, um dos principais desafios das políticas públicas diz respeito justamente à necessidade de territorializar a sustentabilidade ambiental e social do desenvolvimento- o pensar globalmente mas atuar localmente(...) (Guimarães, 2001, p.49)

Em vista disso, é preciso que reflitamos sobre o que tem falhado desde a nossa independência; há mais de três décadas que continuamos fragilizados em quase tudo. Urge que respondamos a questões, como: De onde saímos? Onde estamos? Aonde vamos? E aonde o ambiente nos empurra?

Neste caso, fortalecer a educação superior na GuinéBissau poderia contribuir para que país conseguisse atingir grandes metas em todos os sectores da vida econômica, social, política, ambiental e tecnológica, tais como:

- Construção da Nação Guineense e de uma Sociedade Civil Forte: A Guiné-Bissau é um país constituído por vários grupos étnicos que, por vezes, como defende Augel (2009), o pertencimento étnico é mais claro de que a questão da nação. Assim sendo, a formação dos cidadãos pode contribuir no comprometimento da sociedade a causa nacional, aceitação do outro, a valorização da nossa história e identidade nacional. 
- Afirmação do Estado de direito: O país tem tido problema grave na afirmação da democracia. Assim, tendo maior número de cidadãos formados pode contribuir na consolidação do Estado de direito que o país tanto precisa.

- Melhoraria do Índice do Desenvolvimento Humano (IDH) e Diminuição da Pobreza: De acordo com DENARP II (2011, p.5), "o nível do desenvolvimento humano na Guiné-Bissau continua fraco e precário". A pobreza "afeta dois terços da população do país, nomeadamente a população feminina" (Denarp II, 2011, p.54). Neste caso, a pobreza é um mal que graça a família guineense. O investir na educação superior pode ajudar para formar cidadãos com capacidades de empreender e inovar a fim eliminar a pobreza da maioria da população.

- Elevar a Esperança Média de Vida dos Cidadãos: A esperança média de vida na Guiné-Bissau, segundo DENARP II (2011), é de 48,6. Nesta condição, se o país conquistar ganhos nos pontos acima descritos pode criar o bem-estar às famílias e consequente subida de esperança média de vida do cidadão guineense.

- Maior produtividade na administração pública e privada: $O$ desenvolvimento da educação superior no país pode permitir e encorajar os funcionários públicos e privados interessar-se na formação continuada e permanente.

\section{LIMITES}

Quanto aos limites, os principais notados durante a pesquisa estão demonstrados, abaixo:

- Início tardio da educação superior: A educação superior na Guiné-Bissau teve o seu início tardio, por conta de política colonial que não tinha interesse em desenvolver a educação para além do básico.

- Formação de professores: No que concerne à questão do professor para a educação superior guineense, Augel(2007) mostra-nos que "o número de professores com uma formação pedagógica e acadêmica é mínimo, predominando os professores leigos e com um precário preparo".

Para Odete da Costa Semedo(2011, p. 13-14), acadêmica e ex-ministra da educação, com a qual corroboramos:

Falar da educação na Guiné-Bissau, para a maioria dos guineenses, é falar de problemas que começam com a falta de salas de aulas, de professores qualificados e que terminam com 
uma taxa de repetência, de desistência. É falar de salários baixos e pagos com grandes atrasados.

Nesta perspectiva, a questão de salário baixo pago aos professores da Guiné-Bissau, foi, também, referenciada no relatório do Projeto de Apoio ao Ensino Superior nos Países da UEMOA (Paes, 2010, p.15)“lesenseignantsdusup érieurontdessalairesmensuelsquivarient de 46.ooo FCFA à 100.0oo FCFA enmoyenne. A Tchico TE par exemple, lesalaireendébut de carrière d' unenseignanttitulaire d' unelicenceserait de 72.0Oo FCFA".

Nesta perspectiva, Teta (2009), defende que:

O ponto de partida para o desenvolvimento do ensino superior é o seu docente. Urge criar condições para que os docentes estejam motivados para os desafios de desenvolvimento do ensino superior; Um docente desmotivado é o adiamento do futuro de um povo, de uma nação, enfim, do planeta terra (Teta, 2009, p.37).

Ainda, a falta de cumprimento da Lei da Carreira Docente tem criado instabilidade neste sector, além de motivado sucessivas greves por parte da classe docente, entre outros problemas.

- Acesso à educação superior: Não obstante a cobrança feita quer de matrícula, quer das mensalidades praticadas em algumas instituições de formação pública do país, a procura do ingressar nas IFS tem aumentado gradualmente, como mostra Augel (2009, p.144). PAES (2010, p.9) revela uma situação desfavorável do país, em termos de acesso à educação superior, em relação a outros estados membros da UEMOA (União Econômica Monetária Oeste Africana).

- Infraestruturas de formação:O país tem se deparado com problemas de infraestruturas, visto que é evidente falta de salas de aulas, carteiras, quadros giz e outros, sem contar com a crônica irregularidade de fornecimento de corrente eléctrica nas instituições de formação. Assim sendo, por um lado, muitas instituições alegam, entre outros problemas, receber maior número de estudantes por falta de salas equipadas e, por outro lado, as instituições que se arriscam a receber maior número de estudantes, acabam constituindo turmas de alunos fora de controle pedagógico do professor.

- Baixo orçamento para a educação: O País pouco investe na educação, se comparado aoutros países da região africana. Em vista disso, muitas famílias são obrigadas a investir financeiramente não só na construção 
de escolas, mas também no pagando de propinas aos seus educandos. O documento DENARP II (2011, p.18)faz menção ao investimento pouco ambicioso do governo nas áreas sociais, em relação aos países da sub-região.

\section{DESAFIOS}

Dentre tantos, os desafios a serem enfrentados pela educação superior da Guiné-Bissau, consistem em: formar cidadãos bem qualificados, com espírito nacionalista, com capacidade empreendedora, capazes de viver na diversidade, na democracia, respeitando o próximo, sabendo antecipar problemas e propor soluções, inovar e contribuir para promover o desenvolvimento sustentável do país.

Nesta perspectiva, os desafios da educação superior do País são enormes, quais sejam: maior orçamento à educação; investimento na formação docente e discente e eminfraestruturas; incentivo àmobilidade de docente e de alunos; bolsa de estudo interna e externa; cumprimento das leis sobre o sistema educativo, apropriação e transparência na gestão dos fundos disponibilizados pelos parceiros de desenvolvimento, como UNESCO, Banco Mundial e Fundo Monetário Internacional e outros.

Monteito (2012) defende que a educação superior deve ter a missão de resolver problemas econômicos e promover o desenvolvimento, através de pesquisas levadas a cabo nas instituições de formação superior. Ele atribui à esse nível educacionalda Guiné-Bissau uma relevância extremada, enquanto formador de competências e como disseminador de pesquisas de alto padrão, possibilitando criar e definir políticas, programas e projectos que auxiliem na resolução dos complexos problemas enfrentados pelo país no que tange ao crescimento económico e de desenvolvimento.

- Maior Dotação Orçamentária para Educação: O Orçamento Geral do Estado (OGE) deve consagrar prioridade à educação. Pois, ao longo dos tempos, o montante disponibilizado para educação tem se resumido geralmente às despesas correntes, sem margem para grandes investimentos que comporta este nível do ensino. Vimos anteriormente que o país é considerado um dos que pouco investe na educação em relação a outros países da sub-região africana.

- Formação Docente e Melhores Infraestruturas de Formação: A formação docente é um dos problemas a serem enfrentados, em especial, naeducação superior. A pela falta de qualificação de docentes que atuam nas IFS gera graves consequências para o aprendizado dos alunos e do futuro do país. Nesta condição, o Estado, a sociedade civil e as ONGs devem 
trabalhar para elevação do nível acadêmico aos docentes das IFS para pudermos ter professores a altura de corresponder com as exigências do ensino superior.

- Mobilidade Docente e de Estudantes: A mobilidade docente e de alunos deve ser uma preocupação do Estado, uma vez que estamos em um mundo globalizado em que intercâmbio acadêmico deve ser uma constante para aproveitar as melhores experiências de outros sistemas educativos.

- Bolsa de Estudo Nacional e Internacional : Guiné-Bissau é considerado um dos países mais pobres do mundo. Neste caso, muitas famílias têm limitações para suportar custos de formação dos seus educandos, uma vez que a maioria das IFS cobram as matrículas ou mensalidades. É necessário, pois, que o Estado tenha uma política de bolsas de estudo interno e externo, para alunos com bom aproveitamento, cuja família seja considerada pobre. Ou o Estado deveria assumir todas as despesas da universidade pública, enquanto vetor do desenvolvimento.

- Gestão Transparente das Instituições de Formação do País: Ao longo do tempo, mais da metade do Orçamento Geral do Estado (OGE) é suportado não só pela Comunidade Internacional e amigos da GuinéBissau, mas também pelos parceiros do desenvolvimento, como a UNESCO, o Banco Mundial/FMI, dentre outros, que têm disponibilizado recursos financeiros à educação. Contudo, deve haver capacidades de absorção de recursos financeiros disponibilizados e maior transparência na sua utilização, para poder cultivar a confiança de boa gestão de coisa pública.

- Descentralização das Instituições de Formação: A maioria das IFS concentra-se na capital Bissau, de modo que as regiões do país ficam quase desprovidas delas. Para isso, o Estado deve abrir polos de formação nas regiões do país, em função das potencialidades locais.

- Parceria Internacional entre IFS: O fortalecimento das IFS passa necessariamente pela parceria entre Instituições de Formação Nacionais e Internacionais, na medida em que é necessário a cooperação acadêmica, com intuito de fortalecer e atualizar os conhecimentos, no mundo em rápidas transformações.

- Cumprimento das Leis Aprovadas para o Sistema Educativo: É necessário o cumprimento de leis aprovadas, como: a Lei de Bases do Sistema Educativo, a Lei da Carreira Docente e a Lei do Ensino Superior e da Investigação Científica, dentre outras

Portanto, a observância, dentre outros, dos desafios acima sugeridos para educação superior pode contribuir na afirmação da educação superior do país e o seu consequente desenvolvimento. Na medida em que o desenvolvimento 
requer a formação de atores preparados que possam transformar os recursos naturais em benefício dos cidadãos carentes do país.

\section{À GUIZA DE CONCLUSÃO}

A República da Guiné-Bissau é um país que, desde a sua independência, em 1974, tem enfrentado muitas dificuldades em seu processo de desenvolvimento. Ao longo da sua história, o país tem sido caraterizado, por assim dizer, por sucessivas instabilidades políticas, sociais, econômicas que contribuíram sobremaneira no estado de pobreza em que se encontra o seu povo.

No que concerne à educação, em especial, a educação superior, esta tem enfrentado uma inúmeras dificuldades, a saber: orçamento restrito, falta de docentes qualificados, infraestrutura precária, falta mobilidade docente e de estudantes, bolsa de estudo interna, fraqueza na gestão das instituições de formação e por fim, a falta de cumprimento das leis aprovadas, pelo governo, para o sistema educacional guineense, entre outros. Neste caso, os problemas destacados têm refletido negativamente na qualidade de formação dos estudantes que poderiam no futuro ajudar no desenvolvimento do país.

Assim sendo, a Guiné-Bissau deve saber aproveitar as oportunidades de formação dos cidadãos, através de acordo educacional com países, como: Portugal, Cuba, Rússia, Senegal, China, Brasil, entre outros.

Nessa perspectiva, o desafio do País nos próximos tempos, no nosso entendimento, deve ater-se em criar condições de paz social e apostar na educação do nível básico ao superior, para podermos superar a falta de produtividade em todos os setores da economia nacional, por conta de falta de recursos humanos. Além disso, diminuir a pobreza, dar acesso à saúde, água e luz a sociedade. Ou seja, criar bem-estar aos cidadãos.

Portanto, a educação superior deve ser encarada com preocupação e interesse, quer das autoridades nacionais, da sociedade civil, instituição de formação pública e privada quer das organizações de sistema das Nações Unidas interessadas a educação. É por meio dela, pois, que formaremos cidadãos comprometidos com o País, uma sociedade sem violência, um estado de direito, uma democracia de valor que garanta o exercício democrático dos cidadãos, rumo ao desenvolvimento que se pretende para a República da Guiné-Bissau.

A breve descrição sobre a realidade da educação guineense revela preocupação em relação à falta de qualidade e organização. Por isso, é necessário mais investimentos por parte do Estado, organizações e 
sociedade em geral, para permitir o acesso dos cidadãos para aquilo que é um bem universal, a escola. A escola é um bem comum e dos mais sagrados na vida humana, poisela, além de contribuir com nossas realizações pessoais, pode nos formar para que possamos dar o nosso contributo, mesmo que modesto, para o desenvolvimento do país.

Portando, o Estado da Guiné-Bissau deve fazer muito esforço para investir na educação, se quer realmente cumprir a sua obrigação de contribuir para o desenvolvimento sustentado do país e permitir que os cidadãos estejam preparados para enfrentar as dinâmicas econômicas, sociais, políticas e ambientais do mundo contemporâneo.

\section{REFERÊNCIAS}

AUGEL, Moema Parente. A nova literatura da GuinéBissau. Bissau: INEP, 1998. ColecçãoKebur.

. O Desafio do Escombro: nação, identidade e pós-colonialismo na literatura da Guiné-Bissau. Rio de Janeiro: Garamond, 2007.

. Desafios de Ensino Superior na África e no Brasil: a situação de ensino universitário na Guiné-Bissau e construção da guineidade. Estudos de Sociologia. Rev, do Progr. de Pós-Graduação em Sociologia da UFPE. v. 15. n. 2, p. $137-159,2009$.

(Boletim Oficial, 2011

CÁ, Cristina MandauOcuni. A Trajetória dos Quadros Guineenses Formados e em Formação no Brasil, na Visão de Estudantes e Profissionais de $3^{0}$ Grau. Dissertação(Mestrado). Universidade Estadual de Campinas, Campinas-SP, 2009.

FURTADO, Celso. Introdução ao Desenvolvimento: enfoque histórico-estrutural. 3. ed. Rio de Janeiro: Paz e Terra, 2000.

GUIMARÃES, Roberto P. A ética da sustentabilidade e a formulação de políticas de desenvolvimento. In: VIANA, Gilney; SILVA, Marina; DINIZ, Nilo. O desafio da sustentabilidade: Um debate socioambiental no Brasil. São Paulo: Editora Fundação Perseu Abramo, 2001.

MONTEITO, Hugo. Ensino Superior no Espaço da CPLP: o caso da Guiné-Bissau. Disponível em: www. cplp.org/Admin/Public/DWSDownload.aspx?File...pd (30/12/2012). Acesso em: 15/02/2013.

NASCIMENTO, Elimar Pinheiro do. Educação e Desenvolvimento na Contemporaneidade: dilema ou desafio? IN: BURSZTYN, Marcel, (Org.) et al. Ciência, Ética e Sustentabilidade: desafios ao novo século. $2^{\text {a }}$ edição. São Paulo. 2001. 
ORGANIZAÇÃO PARA A COOPERAÇÃO E DESENVOLVIMENTO ECONÓMICO (OCDE). Relatório 2011 sobre a intervenção internacional em Estados frágeis: República da Guiné-Bissau, OECDE. 2011. Disponível em: http://www.oecd.org/ countries/guinea-bissau/48899975.pdf Acesso em 03/03/2013.

OLIVEIRA, Gilson Batista de. Uma discussão sobre o conceito de desenvolvimento. In: Revista FAE, Curitiba, v.5, n.2, p.37-48. 2002.

POCHMANN, Marcio. Os desafios do Estado na construção do desenvolvimento. Disponível em: http://criseoportunidade.wordpress.com/2010/12/18/osdesafios-do-estado-na-construcao-do-desenvolvimentomarcio-pochmann/. Acessado em 02/03/2013

REPÚBLICA DA GUINÉ BISSAU.Ministério da Educação Nacional - Guia do Professor. Imprensa Nacional E.P., Bissau. 1991.

. Ministério da Educação

Nacional -Plano Nacional da Educação para Todos (EPT),2003, Bissau. Disponível em: www. planipolis.iiep. unesco.org/.../guinea\%2obissau/..Acesso em: 15/02/2013.

. Ministério da Economia do Plano e Integração

Regional - Segundo Documento de Estratégia Nacional de redução da Pobreza - DENARP II. Bissau, 2011.

.Boletim Oficial $N^{\circ} 13$, Lei $n^{\circ} 4 / 2011$. Aprovada a Lei de Bases do Sistema Educativo. INACEP. 2011.

SANHÁ, Alberto. Educação Superior em GuinéBissau. In: Seminário Internacional de educação Superior da Comunidade de países de Língua Portuguesa. PUCRS. 2009. Disponível em: www.pucrs.br/edipucrs/cplp/ educacaosuperior.htm $\square$. Acesso em: 10/05/ 2013.

SEMEDO, Odete Costa. Guiné-Bissau: histórias, culturas, sociedade e literatura. Belo Horizonte: Nadyala, 2011.

SEN, Amartya. Desenvolvimento como liberdade. São Paulo: Companhia de Letras, 2000.

SUCUMA, Arnaldo. Estado e Ensino Superior na Guiné-Bissau 1974-2008. Dissertação (Mestrado) Universidade Federal de Pernambuco, $\mathrm{CFCH}$. Programa de Pós-Graduação em Ciência Política, 2013.

TETA, João Sebastião. Educação Superior em Angola. Disponível em: www.pucrs.br/edipucrs/cplp/ educacaosuperior.htm. Acesso em: 10/03/2013. 
UNIÃO ECONÔMICA MONETÁRIA OESTE AFRICANA (UEMOA) - Projeto de Apoio de Ensino Superior dos Países da UEMOA (PAES). Bissau, 2010.

VERDE, Valéria Villa. Territórios, Ruralidade e Desenvolvimento. Curitiba: IPARDES, fev. 2004.

AGRADECIMENTOS: Os pesquisadores agradecem à CAPES, à UTFPR e à ENA, pelo apoio à realização da pesquisa. 